\title{
BMJ Open When COVID-19 enters in a community setting: an exploratory qualitative study of community perspectives on COVID-19 affecting mental well-being
}

\author{
Naureen Akber Ali (D) , ${ }^{1}$ Anam Shahil Feroz, ${ }^{2}$ Noshaba Akber, ${ }^{3}$ Ridah Feroz, ${ }^{4}$ \\ Salima Nazim Meghani, ${ }^{2}$ Sarah Saleem²
}

To cite: Ali NA, Feroz AS, Akber N, et al. When COVID-19 enters in a community setting: an exploratory qualitative study of community perspectives on COVID-19 affecting mental well-being. BMJ Open 2021;11:e049851. doi:10.1136/ bmjopen-2021-049851

- Prepublication history and additional supplemental material for this paper are available online. To view these files, please visit the journal online (http://dx.doi.org/10.1136/ bmjopen-2021-049851).

Received 05 February 2021 Revised 03 April 2021 Accepted 19 April 2021

Check for updates

(C) Author(s) (or their employer(s)) 2021. Re-use permitted under CC BY-NC. No commercial re-use. See rights and permissions. Published by BMJ.

${ }^{1}$ School of Nursing \& Midwifery, Aga Khan University, Karachi, Pakistan

${ }^{2}$ Community Health Sciences, Aga Khan University, Karachi, Pakistan

${ }^{3}$ Department of Sociology, University of Karachi, Karachi, Pakistan

${ }^{4}$ Aga Khan University Institute for Educational Development, Karachi, Pakistan

Correspondence to

Ms Naureen Akber Ali;

naureenalimeghani@gmail.com

\section{ABSTRACT}

Objective The COVID-19 pandemic has resulted in an increased level of anxiety and fear among the general population related to its management and infection spread. Considering the relevance of present circumstances, we explored perceptions and attitudes of community members towards their mental well-being during the COVID-19 pandemic.

Setting We conducted an exploratory qualitative study using a purposive sampling approach, at two communities of Karachi, Pakistan.

Participants In-depth interviews were conducted with community members including, young adults, middleaged adults and older adults of both genders. Study data were analysed manually using the thematic analysis technique.

Primary outcome The primary outcome is assessing community perception towards their mental well-being amidst the COVID-19 pandemic.

Results A total of 27 in-depth interviews were conducted, between May and June 2020. Three overarching themes were identified: (1) impact of COVID-19 on the mental health of the general communities; (2) current coping mechanisms to adapt to the new reality and (3) recommendations to address the mental health of communities. Generally, community members underwent increased anxiety and fear due to the contagious nature of the virus. Alongside, social, financial and religious repercussions of the pandemic have also heightened psychological distress among community members. However, community members were able to point out some of the coping mechanisms such as getting closer to God, connecting with family, participating in mental health sessions and resetting lives by indulging in diverse activities. Simultaneously, they also recommended the need for remote mental health services for elders and continuous efforts by the government to address the mental health needs of the community.

Conclusion COVID-19-associated mental health consequences have hit every individual in society. The study finding has the potential to guide the development of context-specific innovative mental health programmes to overcome the pandemic repercussions.
Strengths and limitations of this study

- The mental health impact of the COVID-19 pandemic is likely to last much longer than the physical health impact, and this study is positioned well to explore the perceptions and attitudes of community members towards their mental well-being during the COVID-19 pandemic.

- This study will guide the development of contextspecific innovative mental health programmes to support communities in the future.

- To minimise the risk of infection, all study respondents were interviewed online and hence the authors did not have the opportunity to build rapport with the respondents or obtain non-verbal cues during interviews.

\section{BACKGROUND}

The current outbreak of COVID-19 has been declared as a Public Health Emergency of International Concern by the WHO. ${ }^{1}$ The pandemic has not only incurred massive challenges to the global supply chains and healthcare systems but also has a detrimental effect on the overall health of individuals. ${ }^{2}$ A systematic review finding also showed that high rates of psychological illnesses and symptoms were witnessed in the general population of both developed and developing world during the COVID-19 pandemic. ${ }^{3}$ The outbreak has led to lockdowns and has created a negative impact on the societies at large. Most company employees' including daily wage workers have been prohibited from accessing their workplaces or being asked to work from home which has caused job-related insecurities and financial crisis among the communities. ${ }^{4}$ A cross-sectional survey assessed the impact of income loss and social distancing on the quality of life. It was found that almost, $66.9 \%$ of the participants faced drastic loss in their household income due to COVID-19 
pandemic. Besides, factors such as being women, having chronic diseases and living with family size of 3-5 people were related with lower health-related quality of life scores. ${ }^{5}$ Alongside, educational institutions have been closed due to which students have lost their routine of studying and socialising with their peers. ${ }^{6}$ A study also identified that postgraduate students are associated with a higher level of stress, anxiety and depression during COVID-19 lockdown. ${ }^{7}$ While parents have been struggling on creating a structured milieu for their children. COVID-19 has hindered the normal routine life of every individual be it children, teenager, adult or the elderly which may cause florid mental distress. ${ }^{8}$ The crisis is engendering a burden throughout the population particularly in developing countries like Pakistan that face major challenges due to the fragile healthcare systems and poor economic structures. ${ }^{9}$

The pandemic has resulted in an increased level of anxiety and fear among the general population related to its management and infection spread. ${ }^{10}$ Further, the highly contagious nature of the COVID-19 has also escalated confusion, fear and panic among the general population. Moreover, social distancing is often an unpleasant experience for the community members that adds to mental suffering, particularly in the local setting where get-togethers with friends and families is a major source of socialising. ${ }^{8}$ Recent studies also showed that individuals who are following social distancing experience loneliness causing a substantial level of distress in the form of anxiety, stress, anger, misperception and post-traumatic stress symptoms. ${ }^{6} 8$ Also, rumours, myths and inaccurate information about COVID-19 are spreading rapidly with the widespread use of social media and are not only confined to adults but are also carried onto the children that also causes mental distress. ${ }^{11}$ Besides, adhering to all precautionary measures such as wearing mask and proper hand hygiene also serve as stressors for the community people. A cross-country study also showed that implementing precautionary measures (covering mouth during coughing and sneezing, wearing a face mask and hand hygiene) was one of the strongest risk factors of psychological distress among Poland community people. ${ }^{12}$

Mental distress related to the COVID-19 pandemic has been widely witnessed across the globe. The massive lockdown is imposing panic, stress, anxiety, fears and financial insecurities within societies. With the advent of this pandemic in Pakistan, people are restricted at home and are undergoing physical and mental suffering. Moreover, the fear of transmitting disease or family member falling ill is a probable mental function of human nature, but at the same point, psychological fear of the disease generates more anxiety than the disease itself. Therefore, mental health problems are likely to increase in a pandemic situation, and a timely understanding of mental-health status is urgently required for the community people. Thus, considering the relevance of all the above factors, we explored perceptions and attitudes of community members towards their mental well-being during the
COVID-19 pandemic. The present study will potentially guide public health policymakers to plan services that will address the mental health needs of community dwellers which will help to minimise the risk of psychological distress and promote positive coping mechanisms within them.

\section{Research question}

What are the perceptions and attitudes of community members towards their mental well-being amidst the COVID-19 pandemic?

\section{METHODS}

\section{Study design and setting}

This study employed an exploratory qualitative research design using semistructured interviews and a purposive sampling approach. The present study is being stated as per the guidance provided in consolidated criteria for reporting qualitative research as seen in online supplemental file 1 . The study was conducted in two communities of Karachi city. These included Karimabad Federal B Area Block 3 Gulberg Town, Garden East and Garden West area of Karachi city. Karimabad is a neighbourhood in the Karachi-central district of Karachi, Pakistan. It is situated at the south of Gulberg Town bordering Liaquatabad, Gharibabad and Federal B Area. The population of this neighbourhood is predominantly Ismailis. Garden is an up-market neighbourhood, which is in the Karachi, South district of Karachi, Pakistan. It is subdivided into two neighbourhoods: Garden East and Garden West. The population of Garden used to be primarily Ismaili and Goan Catholic but has seen increasing numbers of Memons, Pashtuns and Baloch.

\section{Patient and public involvement}

There was no patient or public involvement in setting the research agenda.

\section{Data collection methods and study participants}

The data collection methods for this formative research included in-depth interviews (IDIs) with community members. The aim of the IDIs was to explore community perceptions and attitudes, towards their mental wellbeing amidst the COVID-19 pandemic. Adult community members who have not contracted the disease were recruited from the urban areas of Karimabad, Garden East and Garden West, as mentioned in table 1. The selected participants have an easy access to internet connectivity within their area. We used the purposive sampling technique to ensure that the target population reflected a diverse range of ages, genders, ethnicities and social backgrounds, as mentioned in table 2. Participants who refused to give consent to participate in this study were excluded. Also, participants were excluded if they have been tested positive for COVID-19 or have been isolated/quarantined because of recent exposure. 
Table 1 Study participants for in-depth interviews

\begin{tabular}{lll}
\hline $\begin{array}{l}\text { In-depth interview } \\
\text { participants }\end{array}$ & $\begin{array}{l}\text { Total } \\
\text { IDIs=27 }\end{array}$ & $\begin{array}{l}\text { Male }(\mathbf{M})=13 ; \\
\text { female }(\mathbf{F})=14\end{array}$ \\
\hline $\begin{array}{l}\text { Young adults (18-35 years) } \\
\begin{array}{l}\text { Middle-aged adults }(36-55 \\
\text { years) }\end{array}\end{array}$ & 8 & Male=6; female=6 \\
$\begin{array}{l}\text { Older adults }(>55 \text { years) } \\
\text { Male=4; female=4 }\end{array}$ & 7 & Male=3; female=4 \\
\hline
\end{tabular}

IDIs, in-depth interviews.

\section{Data collection procedure}

Semistructured interview guide was developed for community members to understand participants perceptions on their mental well-being in light of the current situation as mentioned in online supplemental file 2. The IDI participants were identified and contacted via community WhatsApp group and email. Interviews were scheduled on participants' convenient day and time. Before beginning the interview, the study investigators explained the study objectives and procedures to eligible community members. The consent of the eligible participants was taken before the interview begins, in which participants agreed that the interview can be audio-recorded and written notes can be taken. Trained

\begin{tabular}{|c|c|c|}
\hline $\begin{array}{l}\text { Characteristics of } \\
\text { participants }(n=27)\end{array}$ & & $\begin{array}{l}\mathrm{n}(\%) \text { or } \\
\text { mean } \pm \text { SD }\end{array}$ \\
\hline \multirow[t]{2}{*}{ Gender } & Female & $14(52.0)$ \\
\hline & Male & $13(48.0)$ \\
\hline \multirow[t]{3}{*}{ Age range } & $18-35$ years & $12(44.4)$ \\
\hline & 36-55years & $8(29.6)$ \\
\hline & $>55$ years & 7 (25.9) \\
\hline Mean age & & $39.6 \pm 13.9$ \\
\hline \multirow[t]{5}{*}{ Ethnicity } & Urdu speaking & $5(18.5)$ \\
\hline & Sindhi & $6(22.2)$ \\
\hline & Gujrati & $7(25.9)$ \\
\hline & Katchi & $5(18.5)$ \\
\hline & Punjabi & $4(14.8)$ \\
\hline \multirow[t]{2}{*}{ Marital status } & Single & 9 (33.3) \\
\hline & Married & $18(66.6)$ \\
\hline \multirow[t]{4}{*}{ Education level } & Matriculate & $1(4.0)$ \\
\hline & Intermediate & $4(15.0)$ \\
\hline & Bachelors & $13(48.0)$ \\
\hline & Masters & $9(33.0)$ \\
\hline \multirow[t]{5}{*}{ Occupation } & Private job & $15(56.0)$ \\
\hline & Self-employed & $3(11.0)$ \\
\hline & Home maker & $6(22.0)$ \\
\hline & Student & $2(7.0)$ \\
\hline & Retired & $1(4.0)$ \\
\hline
\end{tabular}

researchers conducted online qualitative interviews via zoom technology or Skype or WhatsApp call function. The interviews were conducted in either Urdu or English language. Study participants were assured that their information remained confidential, and no identifying features will be mentioned on the transcript.

\section{Data analysis}

Study data were analysed manually using the conventional thematic analysis technique. ${ }^{13}$ First, the audio recordings from the interviews were transcribed and then translated into the English language. No identifying characteristics were included in the transcriptions. Transcripts were read several times by four research investigators to develop an interpretation of the community perceptions regarding the COVID-19 pandemic and its impact on their mental health. This involved an iterative process where data were coded, compared, contrasted and refined to generate emergent themes. The transcribed text was divided into 'meaning units' which was later shortened and labelled with a 'code' without losing the study context. Codes were then analysed and grouped into similar categories. In the final step, similar categories were assembled under subthemes and main themes. Two independent investigators performed the coding, and category creation and discrepancies were resolved through discussion until a consensus was reached.

\section{RESULTS}

In this qualitative study, 27 IDIs were conducted, between May and June 2020, with a variety of community members including, young adults, middle-aged adults and older adults of both genders. Data collection was ceased once saturation was achieved. Out of the total of 30 participants, $(n=27)$ were agreed to participate in the study. Each interview lasted around $35-45 \mathrm{~min}$ in duration. The demographic information for the IDIs participants is illustrated in table 2.

Based on the data collection and thematic analysis, three overarching themes were identified: (1) impact of COVID-19 on the mental health of the general communities; (2) current coping mechanisms to adapt to the new reality and (3) recommendations to address the mental health of communities. The themes and categories are presented in table 3 .

\section{Themes 1: impact of COVID-19 on the mental health of the general communities \\ Increased anxiety and fear}

Community members shared that the perceived unpredictability associated with COVID-19 has created stress and fear among individuals. Few community people verbalised that explaining and dealing with children's questions about the current outbreak has further added anxiety in these difficult times. Some community people shared their concerns that the closure of school has led to disruption in the learning of children which may have 
Table 3 Themes and categories

\begin{tabular}{ll}
\hline Themes & Categories \\
\hline $\begin{array}{l}\text { 1. Impact of COVID-19 on mental health of } \\
\text { the general communities }\end{array}$ & Increased anxiety and fear. \\
& Financial hardship amid COVID-19 adversely affecting psychological health. \\
& Effects of media on emotions. \\
& Effects of social isolation on temperament, feelings and emotions. \\
2. Current coping mechanisms to adapt to & Getting closer to God amid COVID-19. \\
the new reality & Connecting online with community members, friends and relatives. \\
& Resetting lives amid COVID-19. \\
& Participating in mental health programmes. \\
3. Recommendations to address mental & Assessing mental health needs of communities. \\
health of communities & Delivering remote mental health interventions for elderly. \\
& Role of government to support mental health of communities.
\end{tabular}

induced anxiety among parents. These all worries and fears have led to a sense of unpredictability about the future, and life after the pandemic. Highlighting these points, a respondent stated:

Obviously there is so much uncertainty about the future ... when this will end? How many people will die? How world will look after this pandemic? (IDI-16)

Another fear that community people stated was the lack of adherence to precautionary measures, which may result in rapid transmission of the virus leading to an increased number of cases and loss of lives. Some participants also expressed that being more meticulous in complying with all safety measures against COVID-19 has raised their frustration and stress level. A similar thought is discussed by a respondent:

Even if you go to the grocery shop you need to be extra careful about wearing masks, maintaining distance, cleaning hands ... which adds to the stress... On the other hand, other people are not following any measures which can eventually get us into trouble. (IDI-20)

While some community members pointed out that they are frightened or scared because currently there is no treatment or vaccine against COVID-19 to control its rapid transmission. Few community individuals also shared that irrespective of disease exposure, they experience dread and anxiety from falling sick and tend to feel false symptoms of disease within them as one participant verbalised:

If you get little flu or a sneeze, it strikes your mind towards COVID-19 symptoms. Even on little body ache...one feels like having COVID-19 symptoms. (IDI-19)

Further, some community members related their fear and anxiety with their risk of getting an infection from the workplace and transmitting it to their families, particularly the elderly, children, or people with compromised immune function. Some community people also voiced their concern that many private hospitals have been unable to accept and manage new patients with COVID-19 which also induces a panic situation among community members. Expressing similar concerns, a participant revealed:

I am scared about my family ... My father is a chronic kidney patient; his immunity is very low. There is a fear that if he will get infected ...Will there be any space in the hospital. Further, how he would go through the entire process as he is already immunecompromised... So, there is a fear of losing my father or losing any other family member. (IDI-25)

\section{Financial hardship amid COVID-19 affecting psychological health} Many community members mentioned that the current pandemic has affected the global economy which will undoubtedly lead to financial losses impacting individuals financially, mostly daily wages workers. Dialogue with the community people indicated that their business is either on hold or concluded due to which individuals face difficulty in making their ends meet. Some of the community individuals also revealed that they faced layoffs or salary deductions in these challenging times. This has eventually affected the economic conditions of the family and they stated that they will have to start over again to get settled in their lives. Highlighting these points, a respondent stated:

We have a garment shop and we thought to earn well in Ramadan. But due to COVID-19, the shop was closed and we were not able to earn even during the peak time. It seems that we would have to wait for a year to get back to the normal routine. (IDI-17)

Moreover, the financial hardships related to the pandemic have translated into widespread emotional distress and increased risk for a psychiatric condition. Similar comments on the experience of mental distress are discussed by a participant:

Many people have lost their jobs...no money to buy grocery and to run house... These people are 
suffering from anxiety and depression. I have heard that few people have attempted suicide because they have no money to survive in this world. (IDI-5)

Restrictions to routine religious practices affecting mental health A number of mass prayers and gatherings in religious places are prohibited which was the source of internal satisfaction and get-together for many individuals, resulting in mental sufferings among community people. Community members verbalised that they used to spend their quality time in the prayer hall to gain strength and positive energy. Highlighting this point, a respondent verbalised

I miss my prayer hall (Jamat Khana). Closure of prayer hall has been very difficult as there is a feeling of incompleteness and dissatisfaction. (IDI-11)

During interviews, many community members also gave insight regarding traditional burial and funeral practices that has been halted due to COVID-19. They shared their concerns that burial practices such as ritual wash (ghusl), shrouding/covering the body (kafan) and funeral prayers could not be performed for the deceased in the current situation. Further, they shared that they are unable to counsel and provide moral support to the bereaved family members. This has heightened their fear and anxiety level and they are scared of dying in this way. This point was illustrated by a respondent who stated:

I have observed that ritual wash is not given to the dead body because of the current situation. I don't want to die like this. I believe burial practices and rituals are so much necessary for the deceased. (IDI-11)

\section{Effects of media on emotions}

Community members mentioned that there is no source of entertainment because all types of media are currently displaying information related to the COVID-19 pandemic. Majority of the community members shared that they are uncertain about the source and authenticity of the information provided by the media. Highlighting this view, a participant expressed:

Media used to entertain us in diverse ways but nowadays all kinds of media are focusing on COVID-19 cases and mortality rates .... further media exaggerate the information about COVID-19 and present to us which has negatively affected us. (IDI-21)

Many individuals shared that the repeated media exposure about COVID-19 has enhanced their psychological distress. They are overwhelmed with misinformation and rumours which impaired their concentration and daily functioning. During the interviews, a community participant shared:

Media has negatively affected us. Media such as news channel has a devastating impact on everyone particularly senior citizens who are at home. If I talk about my mother-in-law, she keeps on watching the news and that has disturbed her so much. She is not coming out of this trauma (COVID-19) ... She is not even coming out of her bed or not even meeting anyone due to the influence of media. (IDI-4)

Some community people notified that media can work positively on a larger scale to nurture community well-being but unfortunately no such direction has been witnessed from their end. Many community members reported that they are avoiding mass media use to promote their mental well-being and to remain mentally stable. Highlighting this view, a participant expressed:

I don't watch the news on media otherwise I will suffer from depression. It is important that we don't watch the news and take care of ourselves. (IDI-14)

Effects of social isolation on temperament, feelings and emotions Community members highlighted that the major repercussion of the COVID-19 outbreak is a restriction on socialisation. The lack of social interaction has substantially influenced the behaviour of people. This is evident by greater psychological distress in the form of anxiety, anger and irritability that results in increased disputes and domestic violence within the families. Similar feelings revealed by the participant:

Physical connection has been broken down from relatives and friends. Overall, everyone has become irritable even on minor issues because one cannot go out, vent out their feelings and meet friends. This has resulted in disputes within the family on small concerns. (IDI-2)

Few people also expressed that working from home is another challenge as you have to show $24 / 7$ availability. This has increased their burden and caused agitation as they find difficulty in balancing their work and home life together. Some participants also verbalised that their fears and increased agitation have resulted in sleep disruptions and restlessness. Highlighting this view, a participant expressed:

Work from home is another stressful thing for me in this pandemic because there is no time limit. Usually, after office hours we are not responsible for any task or to respond back...But nowadays we have to show our availability every time... even on weekends. (IDI-2)

\section{Theme 2: current coping mechanisms to adapt to the new reality} Getting closer to God amid COVID-19

A fundamental element in adjusting to these detrimental circumstances is coping. Each individual in the community found their coping mechanism to deal with the COVID-19 pandemic. Majority of the community members shared that during these challenging times they have come closer to God by spending more time 
praying and being connected with supreme power. Few community individuals also expressed that religion and faith give them strength, and hope to manage the current stressful situation. Highlighting this thought a participant discussed:

This pandemic has provided us an opportunity to connect with our religion... people should come closer to their religion. If they will timely perform their prayers, then it will automatically reduce more than half of their stress and anxiety in this crisis time. (IDI-22)

\section{Connecting with community members, friends and relatives}

Social-isolation is an unusual experience for an individual however, a supportive environment by the family plays a crucial role to cope during the outbreak. Community members shared that lockdown and social distancing have positive aspects as well; as families spend more time together. Spending quality time with family and relatives can bring a sense of ease and comfort. Further, during these unprecedented times, many families reported the use of online technologies to interact with other relatives and friends. Expressing similar thoughts, a participant verbalised:

In these times, families should get united ... positive point is that people, who were unable to spend time with their family, are now spending quality time with family. Due to COVID-19, we are sitting together, avoiding mobile phones and doing table talk. Before COVID-19, I was connected with the world. But I had no idea what is happening at my home. COVID-19 has brought this positive change in life. (IDI-17)

\section{Resetting lives amid COVID-19}

Some of the respondents verbalised that setting up a daily routine like indulging in household chores (cleaning and cooking) helped them to spend their time productively. Others highlighted that they spent time on hobbies such as reading, writing, listening to music, singing, photography, playing indoor games, performing home workouts (exercises and yoga) to stay active and motivated. While some of the individuals used their time effectively in distance learning courses and gaining new skills. A participant shared:

Now a day, I am doing a lot of activities with my daughter. We are doing the artwork (painting) and learning new kinds of painting. I and my daughter have also learnt baking during this lockdown period. Other than that, we are playing different games such as Ludo to keep ourselves busy. (IDI-3)

\section{Participating in mental health programmes}

During these difficult times when there is a deluge of information on COVID-19, community members stated that there is a need to divert their minds by planning strategies and programmes that promote their mental wellbeing. Some community people shared that to overcome anxiety, fear and stress in this pandemic, mental health programmes are initiated by some community leaders and volunteers. These programmes were reported to be useful as they guide people to cope positively and are very helpful for those who are depressed and anxious. Highlighting these views, a community participant verbalised:

Last Sunday, I attended a psychologist session on 'Mindfulness journey to a peace full life', organised by my community. It was a very good programme that guided us on how to be positive. The session focused on the issue of anxiety and stress in this pandemic situation. The session helped in developing a sense of optimism and broadening the horizon of our perceptions. These different types of sessions are running in our community which are very helpful for us to cope in present time. (IDI-5)

\section{Theme 3: recommendations to address the mental health of communities}

\section{Assessing mental health needs of communities}

Some community members shared that mental health issues are considered taboo in our society and people usually avoid talking about them. In that regard, community people pointed out that it is fundamental to assess the mental health needs of the community to plan and design appropriate mental health services. Alongside some community members mentioned that these mental health programmes will also be beneficial for the patients with COVID-19 and their family members. Highlighting these points, a respondent stated:

I believe that if there will be any survey or study conducted to understand the effects of COVID-19 on general population ... The results of the survey will certainly reveal that COVID-19 has more effects on mental health as compared to the physiology of a person. Therefore, the government should conduct the survey and identify the households that have mental health issues and should send flyers or brochures that help them in coping. (IDI-15)

\section{Delivering remote mental health interventions for the elderly}

Most of the community members expressed that the long-term impact of the pandemic would be stressful for every individual particularly elders who are vulnerable given their weaker immune systems. Some community members conveyed that the current pandemic has called on great transformation in terms of delivering remote mental health services via using basic technologies such as the telephone, SMS (short message service) and radio. However, there is a lack of opportunities to monitor the psychosocial needs of elders and deliver support to them.

There are different mental health programmes and sessions which are organised by our Jamati institutions. But we are not providing any mental health 
session for our mass population that is our senior citizens or elder people. (IDI-2)

\section{Role of government to support the mental health of communities}

During the interview, community members notified that the government is only providing awareness about COVID-19 and are not focusing on the psychological needs of the community members. Few community individuals also mentioned that no funding is allocated by the government to tackle the mental health challenges of the community in this outbreak. In this context, many community people recommended the need for quality mental health services from the government at the national and provincial levels. Expressing similar views, a participant mentioned:

Government is not considering mental health issues. They should start mental health programmes which could include online counselling sessions or programmes that could lighten the moods of the general population. They can also raise mental health awareness via talk shows or through any other activity... government can use media to raise awareness and conduct mental health programmes. (IDI-7)

\section{DISCUSSION}

The current study aimed to explore the perceptions and attitudes of community members towards their mental well-being in light of the current pandemic. The study was conducted about 4 months after the primary episode of the COVID-19 pandemic and 2months after the virus hit Pakistan. The research highlighted the mental health challenges faced by the community members in this unprecedented time, alongside strategies and future recommendations to cope with the current crisis.

The study findings revealed that community participants experienced the feeling of anxiety and chaos due to the outbreak. The individuals' emotional reaction and sense of danger stemmed from their concerns regarding their health as well as their family members. Evidence also suggests that there is increased anxiety and fear among people that have been in contact with the suspected COVID-19 individuals or with any infected material. ${ }^{14}$ Community people were fearful of the increasing number of cases and high mortality rate in the country due to lack of adherence to precautionary measures. Literature also pointed out that following precautionary measures, along with the good level of confidence in doctors' diagnosing the COVID-19 virus were found to be protective factors of psychological distress. ${ }^{15}$ While the uncertainty of the pandemic progression and fears to settle down their lives in this disaster caused more mental suffering on them. Recent studies conducted in Italy and Iran also showed that fear of COVID-19 was associated with depression and anxiety among the general population. ${ }^{10} 16$ Similarly, a study conducted on the population of seven middle-income countries of Asia also showed that participants from Pakistan reported the second-highest scores on depression, anxiety and stress (DASS-21) tool. ${ }^{17}$

One of the major repercussions of the COVID-19 outbreak is the social distancing and isolation that have been widely implemented to counter the present crisis. The local government has limited social mobility by employing diverse measures such as the closure of schools, colleges and universities, banned on public gatherings, religious places and unessential workplaces, restricting public transportation, travels and limiting social contacts. This has eventually hampered an individual's source of happiness, connectedness and sense of internal satisfaction. ${ }^{18} 19$ A study also showed that long home-stay, current quarantine, unnecessary fear and discrimination were significantly related to the moderate-to-severe level of stress, anxiety and depression. ${ }^{20}$ Our study findings showed that community members felt overwhelmed by staying at home and they experienced frustration, agitation/anxiety, boredom and loneliness due to lack of physical interaction. A systematic review also reported an association between social isolation and loneliness with impaired psychological well-being. ${ }^{8}$

The closure of prayer halls and prohibition of congregational funeral prayers during the COVID-19 pandemic was another overwhelming concern for many community members. The study finding showed that community people were distressed as they were unable to bury their loved ones or counsel the deceased family members following their religious burial rites. This has raised the sense of shock, and pain among individuals in the society and they were scared of dying in such circumstances. Similar evidence was reported by Wallace $e t a l^{21}$ families that were unable to grieve as per traditional funeral practices or being unable to attend a loved one's burial undergo a feeling of grief and sorrow.

Our study found that the pandemic has caused significant financial disruption among the community members. It was identified that many families were struggling hard in the present time due to financial insecurities including unemployment, and salary deduction. This has caused increased anxiety and depression among families that leads to longlasting negative mental health consequences. Emerging evidence also suggested similar findings that most of the study participants felt anxious about economic restraint throughout lockdown and nearly one-fourth suffered from depressive symptoms. ${ }^{4}$ Further, in the light of the widening financial crisis and unpredictability surrounding this outbreak, suicidal attempts may emerge as one of the emerging threats among the community. ${ }^{22} 23$

Interestingly, the COVID-19 has another challenge in the present age of social media. Our study determined that community people being confined to four walls rely on diverse modes of media (electronic and print media, as well as social media) to receive up-to-date information, but they are often overloaded with false information and rumours. This overwhelming or exaggerated information from the media shaped the risk perception of community members that give 
rise to epidemic-related emotion, creating fear, anxiety and stress. The finding is consistent with the studies conducted in China, and India that also related increased frequency of media exposure with the higher anxiety level among the public. ${ }^{24}{ }^{25}$ Additionally, many community members inferred the presence of physical or somatic symptoms with COVID-19 infection that heightened psychological distress among them. Literature also notified that physical symptoms that resemble with COVID-19 virus were related to a perceived effect of the pandemic and resulted in severe mental health consequences. ${ }^{26}$

Although the COVID-19 illness in its first instance seems like a physical health crisis it has devastating repercussions on mental health. However, in this unstable condition, many individuals have adopted diverse lifestyle-related measures to cope with the circumstances and ease the suffering. Many community members took support from their religious practices and beliefs to cope in this stressful time. Literature also reported that community adults considered current stressful time as an opportunity to deepen their spiritual faith or personal connection with God through prayer, meditation and reciting scriptures that nurtures the soul. ${ }^{19}$

Further many isolated individuals engaged themselves in diverse tasks or activities to live their best possible life. Many community members carried on their hobbies including painting, reading, writing, listening to music or motivational videos, singing, playing an instrument, cooking and exercise and learning new skills via online courses to spend their spare time productively. This sort of behavioural activity helped to divert the mind of the person and create positive emotions that enable individuals to bounce back from negative feelings and lessen their psychological distress. ${ }^{27}$ Additionally, in the current situation, many families got a chance to spend quality time with each other that brought harmony and positivity within them. This finding is also consistent with the literature. $^{28}$

The study finding revealed that the community leaders and volunteers organised different mental health sessions for community people through online mediums. These sessions are essential during pandemics as they helped to reduce mental suffering and promoted adaptive coping strategies. However, participants also notified that there is a lack of provision of mental health services for elderly who lived alone and are now being forced to stay in their homes. Evidence also suggests that vulnerable groups including elders are restricted to their households during the pandemic can have devastating mental health outcomes. ${ }^{29}$ The participants also voiced their concerns that government officials are not providing any psychological services to the community on a larger scale.

In this regard, our study also reported some recommendations to address the mental health needs of the communities. Community participants suggested the need of developing mental health assessment tools along with needbased interventions at the national and provincial levels to mitigate long-lasting mental health effects. WHO has also emphasised taking the essential provisions to deal with the psychological consequences of COVID-19. ${ }^{30}$ Our study participants suggested the need for remote mental health programmes for the entire community particularly elders via using basic technologies such as the telephone, SMS and radio. National broadcasting via television (TV) or radio is a significant tool to motivate people in present times of hopelessness. ${ }^{31}$ These platforms can be served as a powerful medium for creating awareness and arranging counselling sessions by different psychiatrists or psychologists. Further, the nationalised TV or radio can also arrange diverse activities (patriotic songs, shows or movies) that will lessen stress among people and create a sense of unity within them. Similarly, the religious scholars on media can be very helpful to motivate the masses and boost their morale to face crises. ${ }^{32}$ Therefore, mass media can be used as an effective information platform that will convey timely health-related messages about pandemic and assist in reducing mental distress. ${ }^{33}$ Alongside, community service workers can also assist the community by providing authentic health information and education that will lessen their anxiety level. ${ }^{34}$ The present study also suggested the need for psychological helplines for mental health counselling related to COVID-19. While, in this period of social distancing, introducing innovative medium (telehealth) in healthcare services can also provide effective psychological support services for communities that are affected by the COVID-19 pandemic. ${ }^{35}$ However, this calls for strategies that will strengthen the operational capacity of the healthcare system, that is, enhance health expert's quality and quantity, provision of proper medical supplies, allocation of administrative staff and development of training programmes. ${ }^{36}$ Therefore, as suggested by our study participants that allocation of proper funding by the government is pivotal to provide quality mental health services

\section{STRENGTH AND LIMITATIONS}

This is one of the few studies that have explored community perception regarding COVID-19 and its impact on mental well-being. This study has some limitations. Given the nature of the disease, all interviews were conducted online so the researcher was unable to capture the nonverbal cues of participants. Besides, the findings of the present study should be taken as explorative rather than definitive, as all participants were selected from two localities, it would be better to recruit participants from different areas. Further, the researcher was unable to perform focus group interviews which would have presented in-depth insight. Lastly, future studies are required to understand the psychological impact of this pandemic on the community across time.

\section{CONCLUSION}

This study provides a detailed understanding of community experiences and diverse pandemic-related mental health challenges among young, middle and older age adults in Pakistan. Moreover, the finding suggests that during the outbreak continuous support for psychosocial well-being in all age groups should be of utmost 
priority. Additionally, the current disruptive situation calls for the initiation of novel innovative opportunities to provide mental health facilities that foster effective utilisation of available resources. The finding of this study guides the development of context-specific mental health programmes to overcome the repercussions of the pandemic. These psychological interventions will not only be beneficial during the COVID-19 pandemic but could offer a long-term advantage of strengthening the system.

Correction notice Since this article was first published online the author name Rida has been updated to Ridah.

Contributors NAA and AF designed the study. AF, NAA, NA, RF and SNM collected the data. NA and AF analysed and interpreted the data. NA wrote the first draft of the manuscript. AF and SS have given critical feedback. All authors contributed to reviewing and editing the manuscript.

Funding The authors have not declared a specific grant for this research from any funding agency in the public, commercial or not-for-profit sectors.

Competing interests None declared.

Patient consent for publication Not required.

Ethics approval Ethical approval for this study was obtained from the Aga Khan University Ethical Review Committee (AKU-ERC) (2020-4825-10599). Written informed consent was obtained from the study participants.

Provenance and peer review Not commissioned; externally peer reviewed.

Data availability statement The datasets were collected and analyzed and can be made available from the corresponding author on reasonable request.

Supplemental material This content has been supplied by the author(s). It has not been vetted by BMJ Publishing Group Limited (BMJ) and may not have been peer-reviewed. Any opinions or recommendations discussed are solely those of the author(s) and are not endorsed by BMJ. BMJ disclaims all liability and responsibility arising from any reliance placed on the content. Where the content includes any translated material, BMJ does not warrant the accuracy and reliability of the translations (including but not limited to local regulations, clinical guidelines, terminology, drug names and drug dosages), and is not responsible for any error and/or omissions arising from translation and adaptation or otherwise.

Open access This is an open access article distributed in accordance with the Creative Commons Attribution Non Commercial (CC BY-NC 4.0) license, which permits others to distribute, remix, adapt, build upon this work non-commercially, and license their derivative works on different terms, provided the original work is properly cited, appropriate credit is given, any changes made indicated, and the use is non-commercial. See: http://creativecommons.org/licenses/by-nc/4.0/.

ORCID iD

Naureen Akber Ali http://orcid.org/0000-0001-5442-5598

\section{REFERENCES}

1 World Health Organization. Mental health and psychosocial considerations during the COVID-19 outbreak, 18 March 2020. Geneva: World Health Organization, 2020.

2 Ebrahim SH, Ahmed QA, Gozzer E, et al. Covid-19 and community mitigation strategies in a pandemic. BMJ 2020;368:m1066.

3 Xiong J, Lipsitz O, Nasri F, et al. Impact of COVID-19 pandemic on mental health in the general population: a systematic review. $J$ Affect Disord 2020;277:55-64.

4 Chakraborty K, Chatterjee M. Psychological impact of COVID-19 pandemic on general population in West Bengal: a cross-sectional study. Indian J Psychiatry 2020;62:266.

5 Tran BX, Nguyen HT, Le HT, et al. Impact of COVID-19 on economic well-being and quality of life of the Vietnamese during the National social distancing. Front Psychol 2020;11:565153.

6 Zhou X, Snoswell CL, Harding LE, et al. The role of telehealth in reducing the mental health burden from COVID-19. Telemed $J E$ Health 2020;26:377-9.

7 Le HT, Lai AJX, Sun J, et al. Anxiety and depression among people under the nationwide partial Lockdown in Vietnam. Front Public Health 2020;8:656.
8 Brooks SK, Webster RK, Smith LE, et al. The psychological impact of quarantine and how to reduce it: rapid review of the evidence. The Lancet 2020;395:912-20.

9 van Weel C, Kassai R, Qidwai W, et al. Primary healthcare policy implementation in South Asia. BMJ Glob Health 2016;1:e000057.

10 Soraci P, Ferrari A, Abbiati FA, et al. Validation and psychometric evaluation of the Italian version of the fear of COVID-19 scale. Int $J$ Ment Health Addict 2020:1-10.

11 Kumar A, Nayar KR. COVID 19 and its mental health consequences. $J$ Ment Health 2021;30:1-2.

12 Wang C, Chudzicka-Czupała A, Grabowski D, et al. The association between physical and mental health and face mask use during the COVID-19 pandemic: a comparison of two countries with different views and practices. Front Psychiatry 2020;11:901.

13 Vaismoradi $\mathrm{M}$, Turunen $\mathrm{H}$, Bondas $\mathrm{T}$. Content analysis and thematic analysis: implications for conducting a qualitative descriptive study. Nurs Health Sci 2013;15:398-405.

14 Wang C, Pan R, Wan X, et al. Immediate psychological responses and associated factors during the initial stage of the 2019 coronavirus disease (COVID-19) epidemic among the general population in China. Int J Environ Res Public Health 2020;17:1729.

15 Wang C, Pan R, Wan X, et al. A longitudinal study on the mental health of general population during the COVID-19 epidemic in China. Brain Behav Immun 2020;87:40-8.

16 Ahorsu DK, Lin C-Y, Imani V, et al. The Fear of COVID-19 Scale: Development and Initial Validation. Int J Ment Health Addict 2020;1.

17 Wang C, Tee M, Roy AE, et al. The impact of COVID-19 pandemic on physical and mental health of Asians: a study of seven middleincome countries in Asia. PLoS One 2021;16:e0246824.

18 Ho CS, Chee CY, Ho RC, CS H, RC H. Mental health strategies to combat the psychological impact of COVID-19 beyond paranoia and panic. Ann Acad Med Singap 2020;49:1-3.

19 Koenig HG. Ways of protecting religious older adults from the consequences of COVID-19. Am J Geriatr Psychiatry 2020;28:776-9.

20 Tee ML, Tee CA, Anlacan JP, et al. Psychological impact of COVID-19 pandemic in the Philippines. J Affect Disord 2020;277:379-91.

21 Wallace CL, Wladkowski SP, Gibson A, et al. Grief during the COVID-19 pandemic: considerations for palliative care providers. $J$ Pain Symptom Manage 2020;60:e70-6.

22 Lee SA. Coronavirus anxiety scale: a brief mental health screener for COVID-19 related anxiety. Death Stud 2020;44:393-401.

23 Mamun MA, Ullah I. COVID-19 suicides in Pakistan, dying off not COVID-19 fear but poverty? - The forthcoming economic challenges for a developing country. Brain Behav Immun 2020;87:163-6.

24 Gao J, Zheng P, Jia Y, et al. Mental health problems and social media exposure during COVID-19 outbreak. PLoS One 2020;15:e0231924.

25 Suryawanshi R, More V. A study of effect of corona virus Covid-19 and lock down on human psychology of Pune City region. Studies in Indian Place Names 2020;40:984-94.

26 Wang C, Chudzicka-Czupała A, Tee ML. A chain mediation model on COVID-19 symptoms and mental health outcomes in Americans, Asians and Europeans. Scientific Reports 2021;11:1-12.

27 Polizzi C, Lynn SJ, Perry A. Stress and coping in the time of COVID-19: pathways to resilience and recovery. Clinical Neuropsychiatry 2020;17:59-62.

28 Kar SK, Arafat SY, Kabir R. Coping with mental health challenges during COVID-19. coronavirus disease 2019 (COVID-19. Berlin: Springer, 2020: 199-213.

29 Armitage R, Nellums LB. COVID-19 and the consequences of isolating the elderly. Lancet Public Health 2020;5:e256.

$30 \mathrm{Yao} \mathrm{H}$, Chen J-H, Xu Y-F. Rethinking online mental health services in China during the COVID-19 epidemic. Asian J Psychiatr 2020;50:102015.

31 Latif F, Bashir MF, Komal B. Role of electronic media in mitigating the psychological impacts of novel coronavirus (COVID-19). Psychiatry Res 2020;289:113041.

32 Mumtaz M. COVID-19 and mental health challenges in Pakistan. Int $J$ Soc Psychiatry 2020;289:002076402095448.

33 Tran BX, Dang AK, Thai PK, et al. Coverage of health information by different sources in communities: implication for COVID-19 epidemic response. Int J Environ Res Public Health 2020;17:3577.

34 Le HT, Mai HT, Pham HQ, et al. Feasibility of Intersectoral collaboration in epidemic preparedness and response at Grassroots levels in the threat of COVID-19 pandemic in Vietnam. Front Public Health 2020;8:648.

35 Tran BX, Hoang MT, Vo LH, et al. Telemedicine in the COVID-19 pandemic: motivations for integrated, interconnected, and community-based health delivery in resource-scarce settings? Front Psychiatry 2020;11:564452.

36 Tran BX, Hoang MT, Pham HQ, et al. The operational readiness capacities of the grassroots health system in responses to 
